\title{
Three new species of Simulium (Gomphostilbia) (Diptera: Simuliidae) from Sabah and Sarawak, Malaysia
}

\author{
Hiroyuki TAKAOKA \\ Department of Infectious Disease Control, Faculty of Medicine, \\ Oita University, Hasama, Yufu City, Oita, 879-5593 Japan
}

(Received: 9 February 2009; Accepted: 23 March 2009)

\begin{abstract}
Three new species of Simulium (Gomphostilbia) are described from Malaysia: S. (G.) capillatum sp. nov. from Sabah and Sarawak, S. (G.) auratum sp. nov. and $S$. (G.) fulgidum sp. nov., both from Sarawak. Simulium (G.) capillatum sp. nov. is distinctive in having a hairy thoracic proleg, a marked constriction between the fourth and fifth abdominal segments, and thoracic and abdominal cuticle covered with various shapes and sizes of dark spinous setae. Simulium $(G$.) auratum sp. nov. is characterized by the broad inwardly twisted style of the male genitalia, and $S$. $(G$.) fulgidum sp. nov. by the pupal gill with eight short and slender filaments all arising together from the base as well as the short cocoon. The distributional record of $S$. $(G$.) dentistylum Takaoka and Davies from Sabah is withdrawn.
\end{abstract}

Key words: black fly, Simuliidae, Sabah, Sarawak, Malaysia, taxonomy

The simuliid fauna of Sabah and Sarawak, Malaysia, consists of 28 species in the genus Simulium, of which 12 were placed in the subgenus Gomphostilbia, three in Nevermannia, and 13 in Simulium (Edwards, 1933; Smart and Clifford, 1969; Takaoka, 1996, 2001a,b, 2007, 2008a, b).

In this study, one pupa and three of the four mature larvae collected from Sabah and identified by Takaoka (2001a) as $S$. (G.) dentistylum Takaoka and Davies, originally described from Peninsular Malaysia (Takaoka and Davies, 1995) were reexamined, and the result shows that the pupa is $S$. (G.) parahiyangum Takaoka and Sigit, originally described from Java (Takaoka and Sigit, 1992) and later recorded from Sabah and Sarawak (Takaoka, 2001a, 2008b) and the larvae differ from those of both $S$. (G.) dentistylum and $S . \quad(G$.) parahiyangum. The distributional record of $S$. (G.) dentistylum from Sabah is here withdrawn, and a new species, $S$. (G.) capillatum sp. nov., is described on the basis of these larvae as well as others recently collected from Sarawak. Two more new species belonging to the subgenus Gomphostilbia are also described on the basis of reared adult, pupal and/or larval specimens collected from Sarawak.

The terms for morphological features used here follow those of Takaoka (2003). Type specimens of the new species are deposited at the Department of Infectious Disease Control, Faculty of Medicine, Oita University, Oita, Japan.

\section{Simulium (Gomphostilbia) capillatum} sp. nov.

Simulium (Gomphostilbia) dentistylum (nec Takaoka and Davies, 1995), Takaoka: 2001a: 228-229 (larva).

DESCRIPTION. Mature larva. Body length 5.0-6.0 mm. Body (Fig. 1A) characterized in dorsal view by low round protuberance produced laterally on each side of abdominal segments $2-5$ (though those on segments 2 and 3 less pronounced) and by marked constriction between abdominal segments 4 and 5 having 
pair of transparent round protuberances ventrolaterally on each side (Fig. 1J). Body color (Fig. 1A) greenish-yellow except abdominal segments 1-5 each with reddish-brown marking on each dorsolateral or lateral surface (though those on segments $1-3$ often indistinct), and segments 6-9 each with wide reddish-brown area on dorsal and dorsolateral surface (though those of segments 6 and 7 often irregularly discolored medially). Head capsule uniformly covered with simple minute setae. Cephalic apotome dark yellow to yellowish-brown; spots merged into ground color or some spots faintly negative. Lateral surface of head capsule mostly dark yellow to yellowish-brown except eyespot region white; 2 spots in front of posterior margin slightly positive or indistinct. Ventral surface of head capsule dark yellow to yellowish-brown, with dark brown area on each side of postgenal cleft, and with dark brown elongate spot on each side of postgenal cleft. Cervical sclerites composed of 2 small rod-like pieces, not fused to occiput, widely separated from each other. Antenna composed of 3 segments and apical sensillum, much longer than stem of labral fan, without annular hyaline bands; proportional lengths of 1st, $2 \mathrm{nd}$, and 3rd segments 1.00:0.86: 0.95 ; antenna unpigmented except dorsal surface of 1st segment medium to dark brown. Labral fan with 27-31 main rays. Mandible (Fig. 1B) with 3 comb-teeth, decreasing in length from 1st to 3rd; mandibular serrations composed of 2 teeth (1 large and 1 small); large tooth at acute angle to mandible on apical side. Hy postoma (Fig. 1C) with row of 9 apical teeth, median tooth and corner teeth prominent; lateral margins smooth; hypostomal bristles 4 in row, parallel to lateral margin on each side. Postgenal cleft (Fig. 1C) long, reaching posterior margin of hypostoma; subesophageal ganglion unpigmented, not visible. Thoracic proleg (Fig. 1D) moderately covered with simple and branched colorless setae except anterodorsal surface bare. Pharate pupal gill (Fig. 1E,F) with 8 slender filaments arranged as $[(1+2)+(1+2)]+2$ filaments from dorsal to ventral arising from common basal stalk of moderate length. Thoracic cuticle (Fig. 1G) moderately covered with dark spinous setae of various shapes and sizes dorsally, laterally and even ventrally. Abdominal segments 1-3 sparsely to moderately covered with dark spinous setae of various shapes and sizes similar to those on thorax except intersegmental areas almost bare, and abdominal segments 4-9 (Fig. $1 \mathrm{H}-\mathrm{K}$ ) densely covered with dark spinous setae of various shapes and sizes including largest spinous setae dorsally, laterally and ventrally (though segments 7-9 almost bare ventrally); both sides of anal sclerite (Fig. 1L) moderately covered with dark spinous setae with many branches as well as simple colorless ones. Rectal scales present, colorless. Rectal papilla compound, each of 3 lobes with 10 or 11 fingerlike secondary lobules. Anal sclerite X-shaped, anterior arms nearly as long as or slightly shorter than posterior ones; accessory sclerites absent; sensillum absent. Ventral papillae well developed, conical in shape, and densely covered with branched spinous setae of various sizes on outer surface. Posterior circlet of hooks with $74-76$ rows of up to 13 hooks per row.

Female, male and pupa. Unknown.

TYPE SPECIMENS. Holotype mature larva (preserved in ethanol) collected from a stream (width $0.2 \mathrm{~m}$, water temperature $23^{\circ} \mathrm{C}$, partially shaded, altitude $550 \mathrm{~m}$ ), slowly flowing in a forest, Hot Spring Park, Poring, Sabah, Malaysia, 12. III. 1998, by H. Takaoka. Paratypes: 2 mature larvae, same data as those of the holotype; 3 mature larvae, collected from a trickle (width $0.1-0.3 \mathrm{~m}$, water temperature $21^{\circ} \mathrm{C}$, partially shaded, altitude $980 \mathrm{~m}$ ) slowly flowing along the border of a pasture, Bakelalan, Sarawak, Malaysia, 21. VIII. 2008, by H. Takaoka. [The holotype and 2 paratype mature larvae collected from Sabah are those formerly misidentified as $S$. (G.) dentistylum. The remaining one mature larva collected together with these three mature larvae from Sabah was already used for DNA analysis, therefore not available for the present morphological reexamination. However, this larva would be probably $S$. (G.) capillatum sp. nov.] 

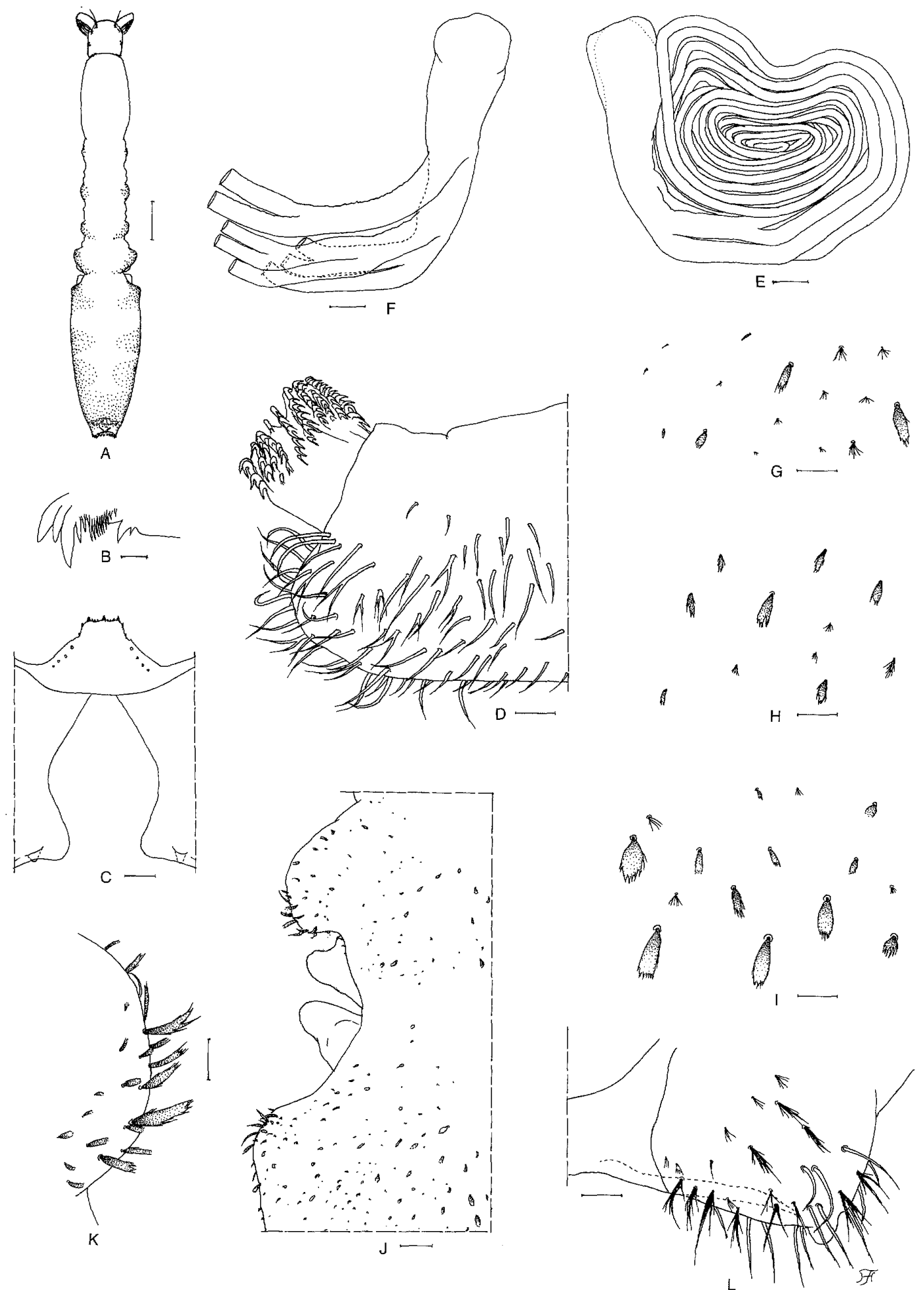

Fig. 1. Mature larva of Simulium (Gomphostilbia) capillatum sp. nov. A, whole body (dorsal view); B, mandible; C, hypostoma and postgenal cleft; D, apical half of thoracic proleg (lateral view); $\mathrm{E}$ and $\mathrm{F}$, pharate pupal gill filaments (left side; E, outer view; F, inner view showing arrangement of 8 gill filaments); G, spinous setae of various shapes and sizes on dorsal surface of thorax; $H$ and I, spinous setae of various shapes and sizes on abdominal segments 4 and 6, respectively; J, parts of abdominal segments 4 and 5 showing deep constriction with 2 transparent projections, and spinous setae of various shapes and sizes (left half and dorsal view); K, spinous setae of various shapes and sizes on lateral surface of abdominal segment 4 (right side and dorsal view); L, area on right side of anal sclerite showing dark branched spinous setae as well as simple colorless setae (dorsal view). Scales. 0.5 $\mathrm{mm}$ for $\mathrm{A} ; 0.05 \mathrm{~mm}$ for $\mathrm{J} ; 0.04 \mathrm{~mm}$ for $\mathrm{C}, \mathrm{E}$ and $\mathrm{F} ; 0.02 \mathrm{~mm}$ for $\mathrm{D}, \mathrm{G}-\mathrm{I}, \mathrm{K}$ and $\mathrm{L} ; 0.01 \mathrm{~mm}$ for $\mathrm{B}$. 
ECOLOGICAL NOTES. The larvae of this new species were found from leaves of trailing grasses and fallen leaves in water. Associated species was $S$. (G.) sheilae Takaoka and Davies.

ETYMOLOGY. The species name capillatum refers to the hairy thoracic proleg. The Latin adjective capillatus means hairy.

DISTRIBUTION. Malaysia (Sabah and Sarawak).

REMARKS. This new species is characterized by the combination of three characteristics: 1) postgenal cleft deep reaching the posterior margin of the hypostoma (Fig. 1C), 2) thorax and abdomen densely covered with spinous setae of distinct shapes on dorsal and dorsolateral surface (Fig. 1 G-L) and even on ventral surface of most segments, and 3) abdomen with a distinct constriction between the fourth and fifth segments (Fig. $1 \mathrm{~A}, \mathrm{~J}$ ). In having these morphological characteristics together with the lack of prominent dorsal protuberances on the abdomen, this new species appears to be very closely related with $S$. $(G$.) dentistylum (Takaoka and Davies, 1995). However, there are clear differences in the shape of the spinous setae on the dorsal and dorsolateral surface of the abdomen (Fig. 1H-L) and the arrangement of the eight filaments of the pharate pupal gill (Fig. 1E, F). The gill filaments of $S$. (G.) dentistylum are arranged as $2+1+3+2$ filaments arising from a very short common basal stalk (Takaoka and Davies, 1995).

This new species appears to be also closely related to $S$. (G.) parahiyangum from Java, Sumatra, Thailand, Peninsular Malaysia, Sabah and Sarawak (Takaoka and Sigit, 1992; Takaoka, 2003, 2008a, b). However, the latter known species is easily distinguished from this new species by the presence of prominent dorsal protuberances on the larval abdomen, the absence of colorless setae on the thoracic proleg, and the short stalks of the dorsal and middle triplet groups and the ventral pair each arising directly from the very short common basal stalk of the pupal gill.

Simulium $(G$.) capillatum sp. nov. is tentatively placed in the batoense speciesgroup, although the female, male and pupa are unknown, in the light of its close resemblance in the larva to $S$. $(G$.) dentistylum and $S$. (G.) parahiyangum, both of which belong to the batoense speciesgroup.

\section{Simulium (Gomphostilbia) auratum sp. nov.}

DESCRIPTION. Male. Body length 2.0-2.3 mm. Head. Wider than thorax. Upper eye clear vermilion, consisting of 15 or 16 vertical columns and 15 horizontal rows of large facets; lower eye dark brown. Face medium brown, white pruinose. Clypeus medium brown, white pruinose, densely covered with yellow short to medium-long hairs and with 3 dark brown simple long hairs near lower margin. Antenna composed of scape, pedicel and 9 flagellomeres, light to dark brown (becoming gradually dark toward apex) except scape, pedicel and base of 1st flagellomere yellow; 1st flagellomere elongate, 1.70 times as long as 2nd one. Maxillary palp with 5 segments, light brown, proportional lengths of $3 \mathrm{rd}, 4$ th, and 5 th segments 1.00 : $1.28: 2.74$; 3rd segment (Fig. 2A) of moderate size; sensory vesicle (Fig. 2A) ellipsoidal, small, 0.20 times as long as 3rd segment, and with small opening. Thorax. Scutum medium brown, thinly white pruinose, shiny when illuminated at certain angle of light, densely covered with golden-yellow short hairs. Scutellum light brown, with golden-yellow short hairs and dark brown upright long hairs. Postnotum medium brown, shiny when illuminated at certain angle of light, and bare. Pleural membrane bare. Katepisternum medium brown, longer than deep, moderately covered with dark brown short hairs and yellow ones. Legs. Foreleg; coxa yellowish; trochanter light brown except inner surface yellow; femur light brown; tibia light to medium brown except extreme base yellowish, moderately covered with golden-yellow hairs on outer surface of basal 3/4; tarsus brownish-black, with moderate dorsal hair crest; basitarsus moder- 
ately dilated, 8.08 times as long as its greatest width. Midleg: coxa medium brown except posterior surface dark brown; trochanter yellow; femur dark yellow with apical cap light brown (though apical extreme yellow); tibia medium brown except basal $2 / 5$ yellowish, moderately covered with golden-yellow hairs on posterior and outer surface of basal $2 / 5$; tarsus medium to dark brown except basal extreme of basitarsus light brown. Hind leg: coxa and trochanter yellow; femur light brown except base yellow and apical cap medium brown (though apical extreme yellow); tibia (Fig. 2B) dark yellow except base yellow and apical $2 / 5$ or little more medium to dark brown, with faint dark subbasal band, and moderately covered with golden-yellow hairs on basal $3 / 5$; tarsus medium to dark brown except basal $3 / 5$ of basitarsus and basal $1 / 2$ of 2 nd tarsomere yellowish-white though base of basitarsus light brown; basitarsus (Fig. 2C) narrow, nearly parallel-sided, 5.74 times as long as wide, and 0.58 times as wide as greatest width of tibia which is as wide as femur; calcipala elongate, extending little beyond middle of 2nd tarsomere, 1.15 times as long as wide, and 0.57 times as wide as greatest width of basitarsus; pedisulcus well developed. Wing. Length 1.6$1.7 \mathrm{~mm}$. Costa with dark brown spinules and hairs except basal portion with patch of golden-yellow hairs. Subcosta bare. Hair tuft on stem vein golden-yellow. Basal portion of radius fully haired; $R_{1}$ with dark brown spinules and hairs; $\mathrm{R}_{2}$ with dark brown hairs only. Basal cell absent. Abdomen. Basal scale yellow, with fringe of golden-yellow hairs mixed with dark brown long hairs. Dorsal and lateral surface of segments 2 and 3 yellow, that of segment 4 yellow except lateral surface of anterior $1 / 3$ light brown, those of segments 5 and 6 yellow or dark yellow except tergal plate and lateral surface of anterior $1 / 3$ to $1 / 2$ light brown, those of segments $7-9$ light to medium brown; segments 2 and 3 covered with yellow hairs interspersed with few to several dark brown hairs dorsally, segments 4-9 covered with yellow hairs and dark brown hairs dorsally and dorsolaterally; segments 2-8 each with pair of shiny dorsolateral or lateral patches. Ventral surface of segments 2-8 yellow to light brown. Genitalia. Coxite in ventral view (Fig. 2D) nearly rectangular, 1.57 times as long as its greatest width; coxite in medial view (Fig. 2E) flattened dorsoventrally; coxite in lateral view (Fig. 2F) somewhat tapered posteriorly. Style in ventral view (Fig. 2D) tapered from base to apex, bent inward, with apical spine; style in medial view (Fig. 2E) nearly parallel-sided, gently curved inward, 0.81 times as long as coxite; style in ventrolateral view (Fig. 2G) wide, nearly parallel-sided from base to little beyond middle, then tapered toward apex, with blunt apex; outer margin sharply angulate; style in lateral view (Fig. $2 \mathrm{~F}$ ) nearly parallel-sided, with apical portion concave; style in end view (Fig. 2 H) with apical portion much narrowed and directed inward. Ventral plate in ventral view (Fig. 2D) transverse, 0.47 times as long as wide, widest near posterior margin, gradually narrowed anteriorly, with anterior margin produced anteromedially, with posterior margin very slightly concave medially, and densely covered with microsetae medially on ventral surface; basal arms of moderate length, nearly parallel-sided; ventral plate in lateral view (Fig. 2I) much produced ventrally; ventral plate in end view (Fig. 2J) nearly inverted-V shaped, and densely covered with microsetae on posterior surface except both lateral areas mostly bare. Median sclerite (Fig. 2I, K) thin, plate-like, wide, slightly sclerotized mediolongitudinally, connected to ventral plate near anterior margin. Paramere (Fig. 2L) of moderate size, each with 3 long and stout hooks and several smaller ones close together near apex. Aedeagal membrane (Fig. 2M) moderately setose, not sclerotized basally (then not forming pigmented dorsal plate). Ventral surface of 10 th abdominal segment slightly sclerotized anteriorly, without distinct hairs near posterior margin on each side. Cercus (Fig. 2N, O) rounded, with 7-10 hairs.

Pupa. Body length $2.2 \mathrm{~mm}$. Head. Integument yellow, moderately covered with small round tubercles; antennal sheath without any protuberances or tubercles; frons with 3 pairs of simple very long trichomes with coiled or uncoiled apices and face with pair of simple very long trichomes with uncoiled apices. Thorax. Integument yellow, moderately covered with round tubercles, with 3 simple very long mediodorsal trichomes with coiled or uncoiled apices, 2 simple anterolateral trichomes ( 1 very long and with coiled apex, 1 long and with uncoiled apex), 1 simple long posterolateral trichome with uncoiled apex and 3 simple ventrolateral trichomes with uncoiled 

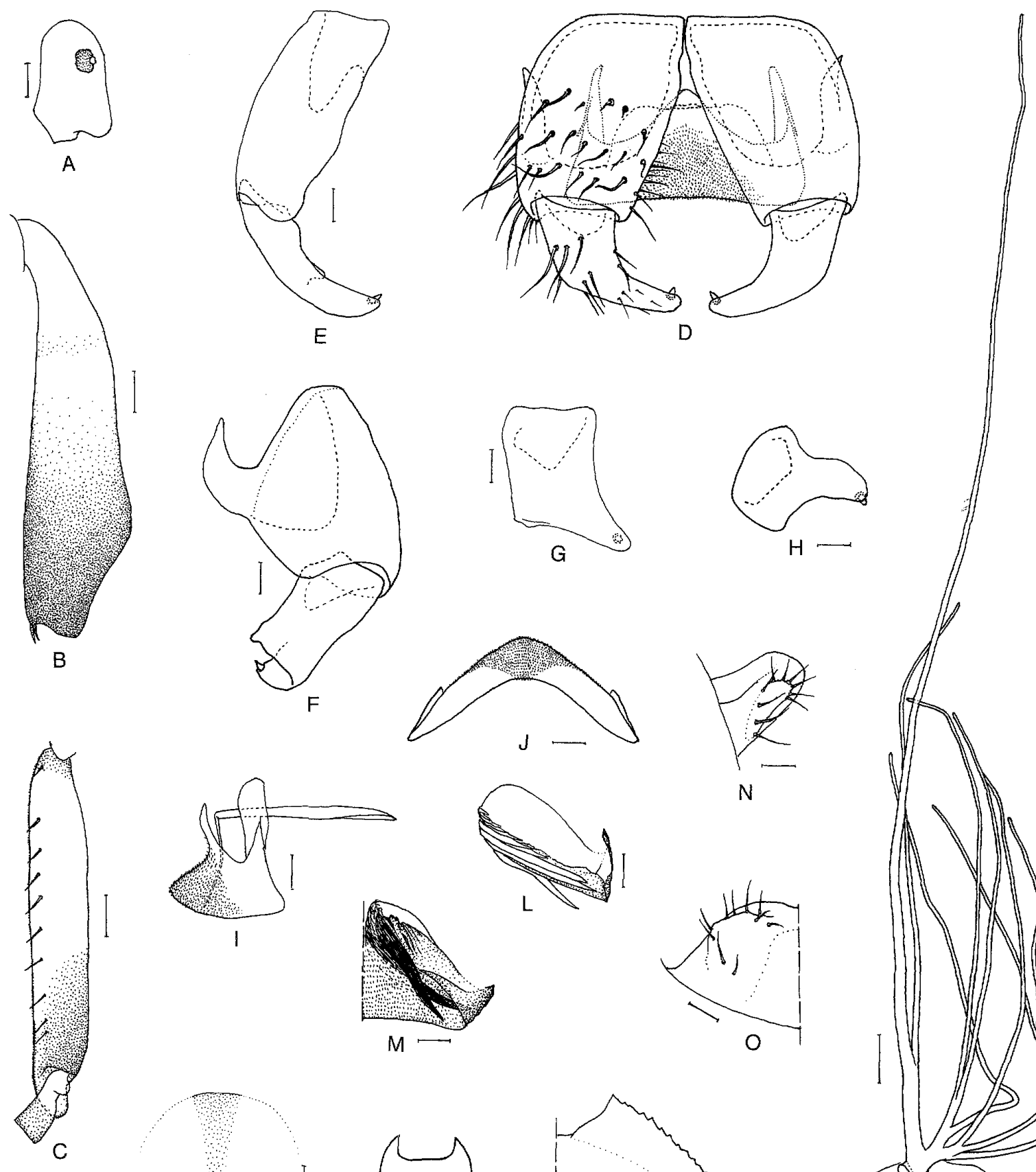

N

FुC
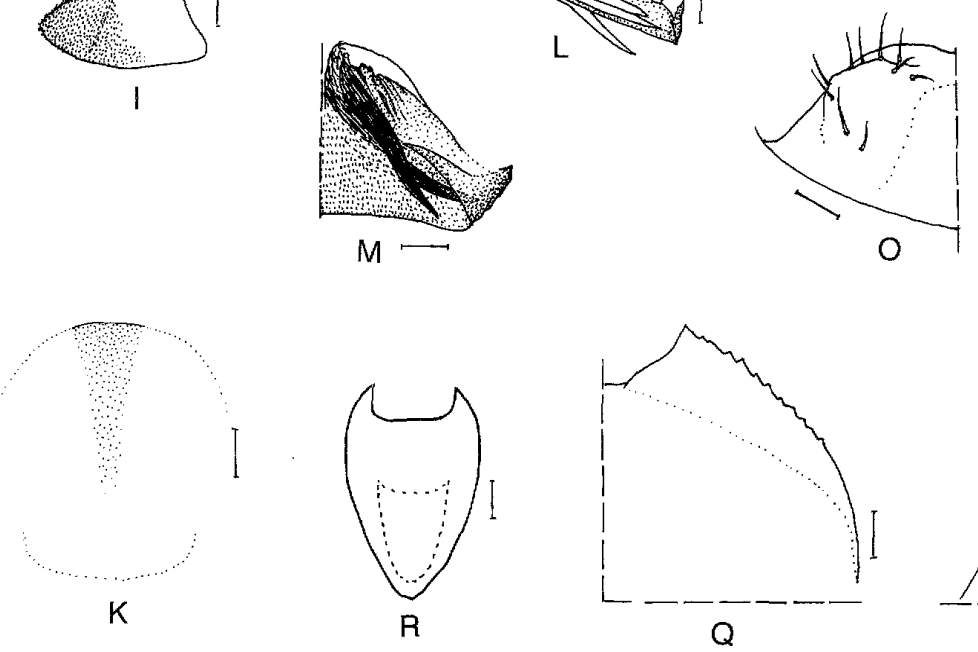

Fig. 2. Male and pupa of Simulium (Gomphostilbia) auratum sp. nov. A-O, male; P-R, pupa. A, 3rd segment of maxillary palp with sensory vesicle (right side and front view); B, hind tibia (left side and outer view); C, hind basitarsus and 2nd tarsomere (left side and outer view): D, coxites, styles, ventral plate and median sclerite in situ (ventral view); E and F, coxite and style (right side; E, medial view; F, lateral view); $G$ and $H$, style (right side; $G$, ventrolateral view; $H$, end view); I, ventral plate and median sclerite in situ (lateral view); J, ventral plate (end view); K, median sclerite (anterior view); L, paramere (right side and dorsal view); $\mathrm{M}$, aedeagal membrane and paramere (left side and end view); $\mathrm{N}$ and $\mathrm{O}, 10$ th abdominal segment and cercus (right side; N, lateral view; O, end view); $\mathrm{P}$, gill filaments (left side and outer view); Q, terminal hook (right side and end view); R, cocoon (dorsal view). Scale bars. $0.5 \mathrm{~mm}$ for R; $0.1 \mathrm{~mm}$ for $\mathrm{P} ; 0.05 \mathrm{~mm}$ for $\mathrm{B}$ and $\mathrm{C} ; 0.02 \mathrm{~mm}$ for $\mathrm{A}$ and $\mathrm{D}-\mathrm{O} ; 0.01 \mathrm{~mm}$ for $\mathrm{Q}$. 
apices (1 long, 2 short) on each side. Gill (Fig. 2 P) composed of 8 slender thread-like filaments, slightly longer than pupal body, arranged in groups of $[(1+2)+(1+2)]+2$ filaments from dorsal to ventral, with somewhat swollen transparent organ ventrally (partially broken) at base; dorsal and middle triplets sharing very short stalk which arises from very short common basal stalk; dorsal triplet composed of 1 individual and 2 paired filaments with very short stalk; middle triplet composed of 1 individual and 2 paired filaments with short stalk; ventral pair with medium-long stalk which is thicker than stalks of dorsal and middle triplets but thinner than interspiracular trunk; all filaments light brown, gradually tapered toward apex; outer filament of ventral pair longest (2.1-2.3 mm long) and thickest (1.5 times as thick as inner filament of ventral pair when basal portions are compared), with marked annular ridges and furrows though becoming indistinct apically; other 7 filaments subequal in length $(1.0-1.2 \mathrm{~mm}$ long, though inner filament of ventral pair slightly longer than others); inner filament of ventral pair and 2 individual filaments of middle and dorsal triplets 1.2 times as thick as 4 paired filaments of middle and dorsal triplets; all 7 shorter filaments with less distinct annular furrows but without annular ridges; cuticle of all filaments densely covered with minute tubercles. $\boldsymbol{A} \boldsymbol{b} \boldsymbol{d} \boldsymbol{d o}-$ men. Dorsally, segments 1 and 2 with no tubercles; segment 1 with 1 simple slender mediumlong hair-like seta on each side; segment 2 with 1 simple slender medium-long hair-like seta and 5 very short setae submedially on each side; segments 3 and 4 each with 4 hooked spines and 1 somewhat spinous very short seta on each side; segment 5 lacking spine-combs; segments 6-9 each with spine-combs in transverse row and comb-like groups of minute spines on each side; segment 9 with pair of distinct flat plate-like terminal hooks extending laterally at base and having weakly serrated outer margin (Fig. 2Q). Ventrally, segment 4 with 1 brown simple short hooklet and few simple slender very short setae on each side; segment 5 with pair of bifid hooks submedially and few simple slender very short setae on each side; segments 6 and 7 each with pair of bifid inner and simple outer hooks somewhat spaced from each other and few simple slender very short setae on each side; segments $4-8$ with comb-like groups of minute spines. Each side of segment 9 with 3 grapnelshaped hooklets. Cocoon (Fig. 2R). Wall-pocket shaped, thickly and neatly woven, widely extending ventrolaterally; anterior margin somewhat thickly woven, without any bulge or projection anterodorsally; posterior $1 / 2$ with floor moderately woven; individual threads visible; $3.0 \mathrm{~mm}$ long by $1.6-1.8 \mathrm{~mm}$ wide.

Female and mature larva. Unknown.

TYPE SPECIMENS. Holotype male with associated pupal exuviae and cocoon (preserved in ethanol), collected from a small stream (width $0.2-0.3 \mathrm{~m}$, stream bed rocky and stony, water temperature $20.0^{\circ} \mathrm{C}$, shaded, altitude $1,000 \mathrm{~m}$ ), slowly flowing in a natural forest, Bakelalan, Sarawak, Malaysia, 21. VIII. 2008, by H. Takaoka. Paratypes: 1 male with associated pupal exuviae and cocoon, collected from a small stream (width $0.2-0.5 \mathrm{~m}$, stream bed sandy, water temperature $21.0^{\circ} \mathrm{C}$, exposed to sun, altitude $980 \mathrm{~m}$ ), slowly flowing down a grassy hill, Bakelalan, Sarawak, Malaysia, 22. VIII. 2008, by H. Takaoka; 1 pupal exuviae and cocoon, same data as those of the holotype.

ECOLOGICAL NOTES. The pupae and pupal exuviae of this new species were collected from grass leaves and fallen tree leaf in the water. Associated species were $S$. (G.) barioense Takaoka and $S$. (G.) kelabitense Takaoka.

ETYMOLOGY. The species name auratum refers to the male scutum densely covered with golden hairs. The Latin adjective auratus means golden.

\section{DISTRIBUTION. Malaysia (Sarawak).}

REMARKS. Simulium (G.) auratum sp. nov. is assigned to the batoense speciesgroup within the subgenus Gomphostilbia in that it has the antennae with 11 segments, the pleural membrane bare, and the slender hind basitarsus (Fig. 2C) in the male, and eight gill filaments arranged in groups of $3+3+2$ filaments (Fig. $2 \mathrm{P}$ ) in 
the pupa.

Simulium (G.) auratum sp. nov. appears to be related to $S$. (G.) epistum Delfinado described from Palawan Island, the Philippines (Delfinado, 1971; Takaoka, 1983) in having the wide male style (Fig. 2G) and the pupal gill composed of one long and seven short filaments (Fig. 2P). However, $S$. (G.) auratum sp. nov. is readily distinguished in the male by the number of large upper-eye facets (15 or 16 vertical columns and 15 horizontal rows in this new species vs. 11 vertical columns and 11 horizontal rows in $S$. (G.) epistum), the color of the abdomen (mostly yellowish in this new species vs. mostly brownish in $S$. (G.) epistum) and the ventral plate which is widened posteriorly in this new species but narrowed posteriorly in $S$. (G.) epistum.

\section{Simulium (Gomphostilbia) fulgidum sp. nov.}

DESCRIPTION. Female. Body length 2.0 $\mathrm{mm}$. Head. Somewhat narrower than width of thorax. Frons narrow, brownish-black, dull, densely covered with yellowish-white scalelike recumbent hairs interspersed with several dark simple long hairs along each lateral margin; frontal ratio $1.70-2.16: 1.00: 3.25-$ 3.92; frons-head ratio $1.00: 5.60-5.79$. Frontoocular area (Fig. 3A) well developed, directed laterally and upwardly. Clypeus brownishblack, densely covered with yellowish-white scale-like long hairs (except area near dorsal margin bare) interspersed with several dark simple long hairs near ventral margin on each side. Labrum 0.70 times as long as clypeus. Antenna composed of scape, pedicel and 9 flagellomeres, medium to dark brown except scape, pedicel and base of 1st flagellomere whitish-yellow. Maxillary palp composed of 5 segments, light to medium brown, proportional lengths of 3rd, 4th and 5th segments 1.00:1.011.07:2.33-2.59; 3rd segment (Fig. 3B) somewhat swollen apically; sensory vesicle (Fig. 3B) ellipsoidal, 0.30-0.34 times as long as 3rd segment, with medium opening medially; right segment 3 separated incompletely from segment 2 , and its sensory vesicle located much more basally (Fig. 3C) in 1 female. Maxillary lacinia with 10 or 11 inner and 12 or 13 outer teeth. Mandible with 20 inner teeth and 3 or 4 outer ones (weakly developed at some distance from apex). Cibarium (Fig. 3D) medially forming round sclerotized plate folded forward from posterior margin, which is partially covered by pair of round moderately-sclerotized elliptical plates; cibarium medially with wellsclerotized longitudinal ridge with forked apex. Thorax. Scutum medium to dark brown, with 3 faint dark longitudinal vittae (1 medial and 2 submedial), shiny, thinly white pruinose, densely covered with yellowish-white scalelike recumbent short hairs interspersed with few dark brown upright long hairs on prescutellar area; scutellum light to medium brown, covered with yellowish-white short hairs as well as dark brown upright long hairs. Postnotum medium to dark brown, bare. Pleural membrane bare. Katepisternum medium brown, longer than deep, moderately covered with dark brown hairs and yellowish fine hairs. Legs. Foreleg: coxa whitish-yellow; trochanter light brown; femur light brown except apical cap medium brown (though extreme tip pale); tibia medium brown except base whitish-yellow, and median large portion on outer surface light brown; tarsus brownishblack, with moderate dorsal hair crest; basitarsus somewhat dilated, 5.40 times as long as its greatest width. Midleg: coxa medium brown with posterior surface brownish-black; trochanter whitish-yellow; femur grayishyellow except apical cap medium brown (though apical extreme pale); femur with patch of dark brown hairs medially appearing to have dark wide medial band; tibia whitishyellow on basal $3 / 5$ with dark subbasal band, and medium brown on apical $2 / 5$; tarsus dark brown with basal $1 / 2$ or little less of basitarsus whitish-yellow. Hind leg: coxa yellow though somewhat darkened along posterior margin; trochanter whitish-yellow; femur light brown with base whitish-yellow and apical cap medium brown; tibia (Fig. 3E) whitish-yellow on basal $1 / 2$ or little less (border not well defined), with light brown subbasal band, gradually darkened toward apical $1 / 4$ and medium to dark brown on apical $1 / 4$ or little more; tibia 

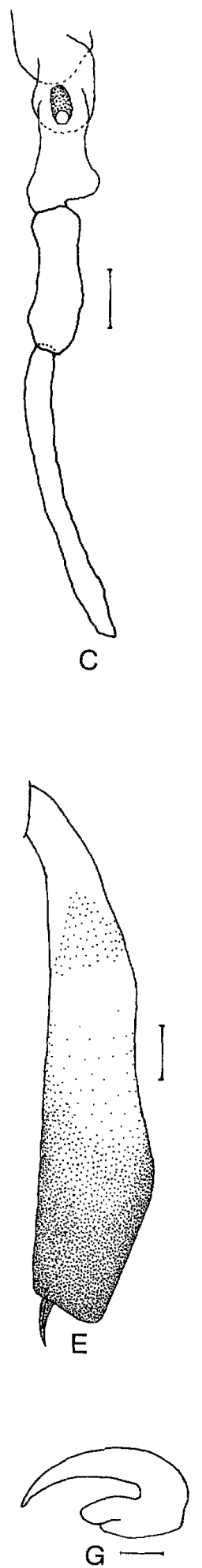
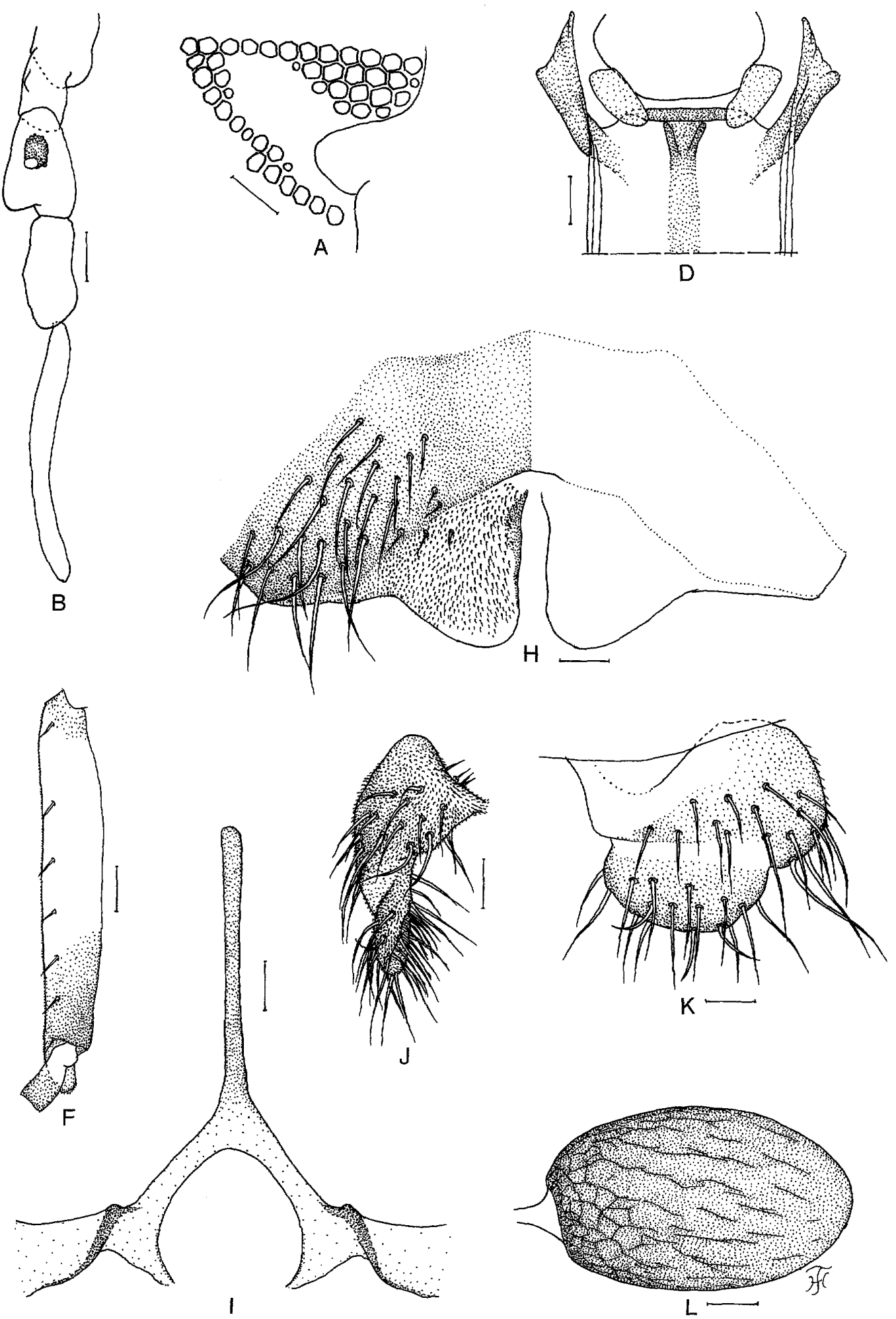

Fig. 3. Female of Simulium (Gomphostilbia) fulgidum sp. nov. A, fronto-ocular area (right side and front view); $\mathrm{B}$ and $\mathrm{C}$, maxillary palp (B, left side and normal; C, right side and abnormal); D, cibarium; E, hind tibia (left side and outer view); F, hind basitarsus and 2nd tarsomere (left side and outer view); G, claw; H, sternite 8 and ovipositor valves in situ; I, genital fork; J and K, paraproct and cercus (right side; J, ventral view; K, lateral view); L, spermatheca (lateral view). Scales. $0.05 \mathrm{~mm}$ for $\mathrm{E}$ and $\mathrm{F} ; 0.04$ $\mathrm{mm}$ for $\mathrm{A}-\mathrm{C} ; 0.02 \mathrm{~mm}$ for $\mathrm{D}$ and $\mathrm{H}-\mathrm{L} ; 0.01 \mathrm{~mm}$ for $\mathrm{G}$. 
densely covered with whitish-yellow fine hairs on outer and posterior surface of basal 3/4; tarsus brownish-black except little more than basal $2 / 3$ of basitarsus (though base light brown), basal $1 / 2$ of 2 nd tarsomere yellowishwhite; basitarsus (Fig. 3F) narrow, nearly parallel-sided, 5.91 times as long as wide, and 0.65 and 0.52 times as wide as greatest width of tibia and femur, respectively; calcipala 1.36 times as long as wide, and 0.50 times as wide as greatest width of basitarsus. All claws (Fig. 3G) each with large basal tooth 0.50 times as long as claw. Wing. Length $1.6 \mathrm{~mm}$. Costa with dark brown spinules as well as dark brown hairs except basal portion with patch of yellowish hairs. Subcosta with dark hairs except near apex bare. Hair tuft on stem vein yellowish. Basal portion of radius fully haired. Basal cell absent. Abdomen. Basal scale dark yellow, with fringe of pale yellow fine hairs. Dorsal surface of abdomen light to medium brown except basal $1 / 2$ of segment 2 grayish-yellow, moderately covered with short dark hairs; tergites of segments 2, 6, 7 and 8 shiny; sternal plate on segment 7 undeveloped. Genitalia. Sternite 8 (Fig. 3H) bare medially, with 20-23 long stout hairs and 3 short hairs on each side. Ovipositor valves (Fig. $3 \mathrm{H}$ ) nearly triangular, with round medioposterior corners, thin, membranous, moderately covered with microsetae interspersed with 2 short setae; inner margins nearly straight or slightly sinuous, moderately sclerotized, and somewhat separated from each other. Genital fork (Fig. 3I) of usual inverted-Y form, with arms of moderate width; arm moderately folded medially, with large projection directed medioposteriorly. Paraproct in ventral view (Fig. 3J) tapered medially, with 18-20 long hairs on ventral and lateral surface, and with 3 or 4 sensilla on anteromedial surface; paraproct in lateral view (Fig. $3 \mathrm{~K}$ ) moderately produced ventrally beyond ventral margin of cercus. Cercus in lateral view (Fig. $3 \mathrm{~K}$ ) rounded posteriorly, 0.4 times as long as wide. Spermatheca (Fig. 3L) ellipsoidal, 1.58 times as long as wide, well sclerotized except duct and small area of juncture with duct unsclerotized, and with many fissures on surface; internal setae absent; both accessory tubes slender, slightly larger in diameter than major one.
Male. Body length $2.2 \mathrm{~mm}$. Head. Much wider than thorax. Upper eye consisting of 10 vertical columns and 10 horizontal rows of large facets. Face brownish-black, white pruinose, not shiny. Clypeus brownish-black, white pruinose, not shiny, densely covered with yellow scale-like short to medium-long hairs interspersed with several dark brown simple longer hairs near ventral margin on each side. Antenna composed of scape, pedicel and 9 flagellomeres, yellow except 2 apical flagellomeres light to medium brown; 1st flagellomere elongate, 1.50 times as long as 2 nd one. Maxillary palp with 5 segments, light brown, proportional lengths of $3 \mathrm{rd}$, 4 th, and 5th segments $1.00: 1.16: 2.98$; 3rd segment (Fig. 4A) widened apically; sensory vesicle (Fig. 4A) ellipsoidal, small, 0.24 times as long as 3rd segment, and with medium-sized opening. Thorax. Nearly as in female except scale-like recumbent short hairs and upright long hairs on scutum and short hairs on scutellum golden-yellow. Legs. Color and shape (except claw) nearly as in female except slight differences: fore basitarsus moderately dilated, 6.71 times as long as its greatest width; hind basitarsus (Fig. 4B) whitish-yellow on basal $3 / 5$, nearly parallel-sided, 5.73 times as long as wide, and 0.61 and 0.50 times as wide as greatest widths of tibia and femur, respectively; calcipala elongate, extending little beyond middle of 2nd tarsomere, 1.25 times as long as wide, and 0.47 times as wide as greatest width of basitarsus. Wing. Length $1.5 \mathrm{~mm}$; other features as in female except subcosta bare. Abdomen. Basal scale dark yellow, with fringe of yellow long hairs. Dorsal surface of abdomen medium brown except segments 2 and 3 yellow, covered with dark short to long hairs except hairs on segments 2 and 3 mostly yellow; segments 2-9 each with pair of shiny dorsolateral or lateral patches, of which those on segments 24 broadly or narrowly connected in middle to each other. Genitalia. Coxite in ventral view (Fig. 4C) nearly rectangular, 1.75 times as long as its greatest width, and in medial view (Fig. 4 D) somewhat flattened dorsoventrally. Style in ventral view (Fig. 4C) slender, tapered toward apex, gently curved inward, with apical spine (though additional spine present near apex on right style); style in medial view (Fig. 4D) slender, nearly parallel-sided, 0.89 times as long as coxite, gently bent inward; style in ventrolateral view (Fig. 4E) slightly narrowed 


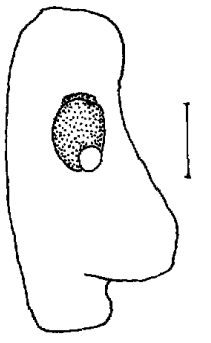

A

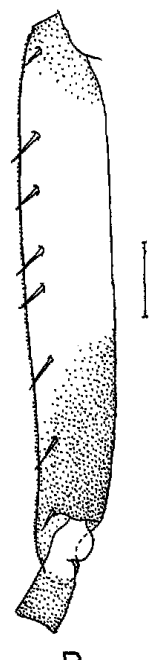

B
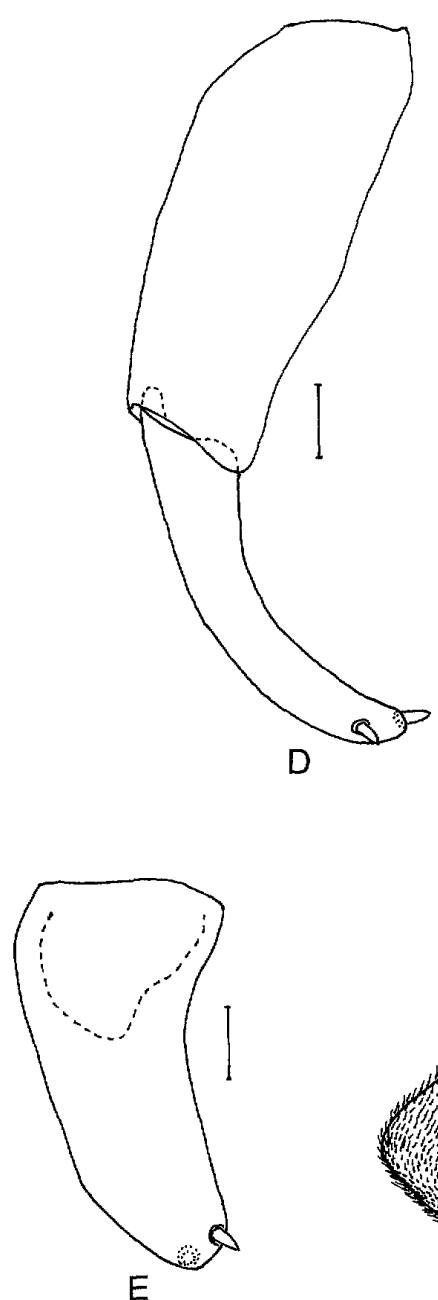

$E$
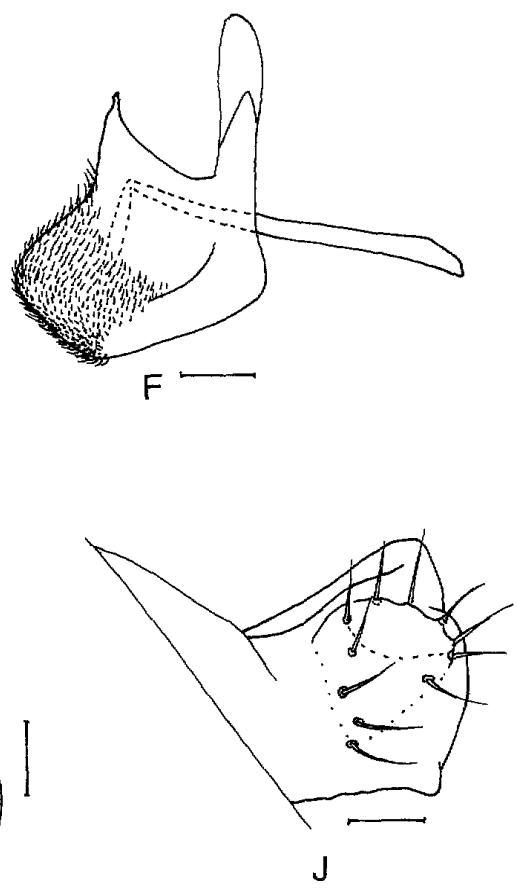

C
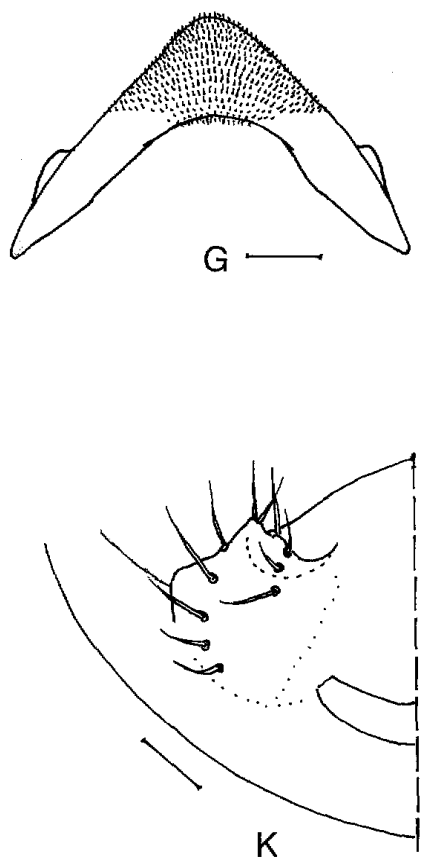

G

K
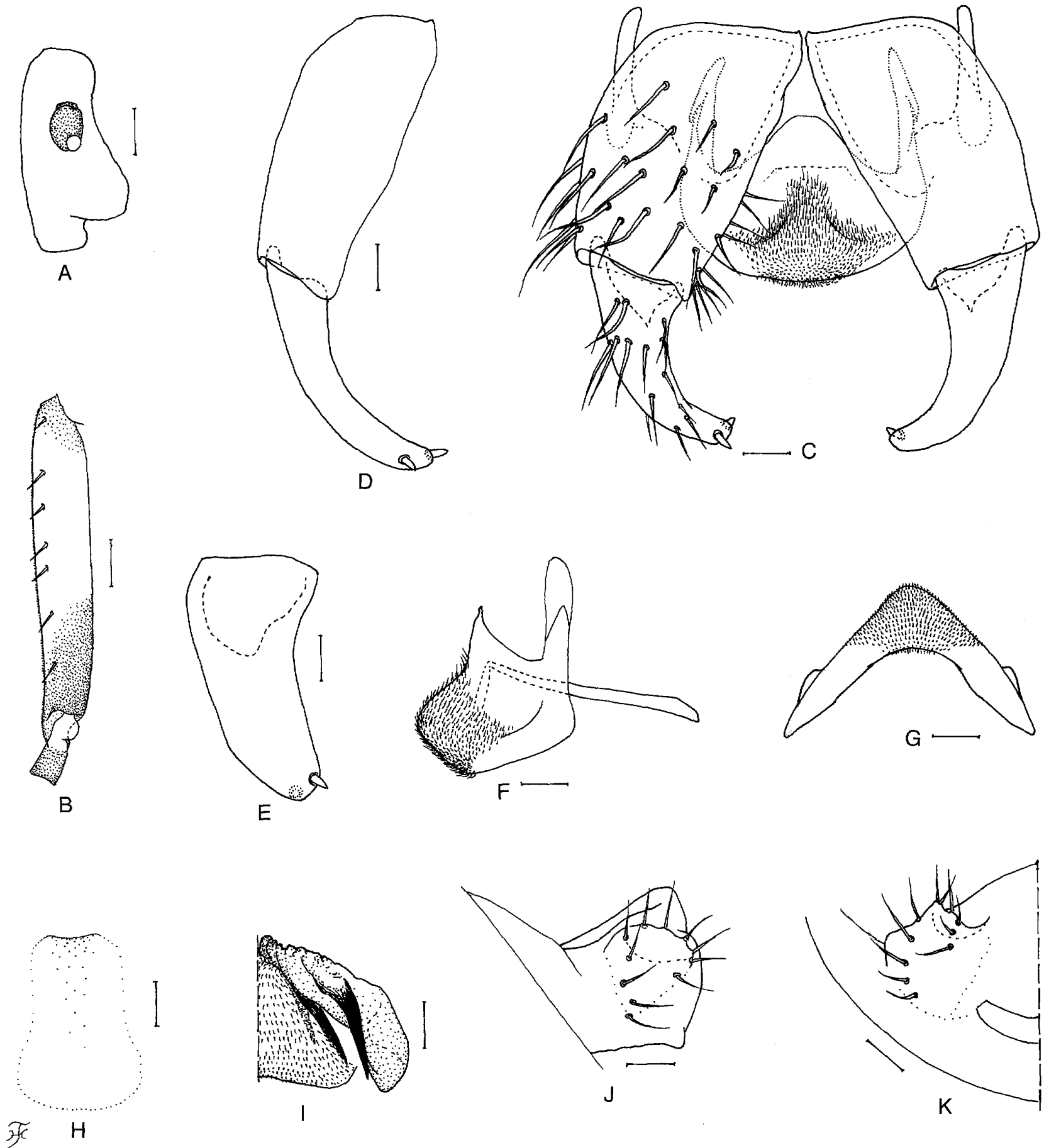

Fig. 4. Male of Simulium (Gomphostilbia) fulgidum sp. nov. A, 3rd segment of maxillary palp with sensory vesicle (right side and front view); B, hind basitarsus and 2nd tarsomere (left side and outer view): C, coxites, styles and ventral plate in situ (ventral view); D, coxite and style (right side and medial view); E, style (right side and ventrolateral view); $\mathrm{F}$, ventral plate and median sclerite in situ (lateral view); G, ventral plate (end view); $\mathrm{H}$, median sclerite (anterior view); I, aedeagal membrane and paramere (left side and end view); $\mathrm{J}$ and $\mathrm{K}, 10 \mathrm{th}$ abdominal segment and cercus (right side; J, lateral view; $\mathrm{K}$, end view). Scale bars. $0.05 \mathrm{~mm}$ for $\mathrm{B} ; 0.02 \mathrm{~mm}$ for $\mathrm{A}$ and $\mathrm{C}-\mathrm{K}$.

from base to apical $1 / 4$, then tapered toward apex, with round apex. Ventral plate in ventral view (Fig. 4C) transverse, 0.67 times as long as wide, with anterior margin produced anteromedially, and posterior margin round (though nearly straight when slightly inclined anteriorly), densely covered with microsetae on ventral surface except anterior and lateral surface widely bare; basal arms of moderate length, very slightly converged apically; ven- 
tral plate in lateral view (Fig. $4 \mathrm{~F}$ ) much produced ventrally; ventral plate in end view (Fig. $4 \mathrm{G})$ triangular, densely covered with microsetae on posterior surface except both lateral areas mostly bare. Median sclerite (Fig. 4F, H) thin, plate-like, wide, connected to ventral plate near anterior margin. Paramere (Fig. 4I) of moderate size, with 3 distinct long and stout hooks. Aedeagal membrane (Fig. 4I) moderately setose, not sclerotized. Ventral surface of 10th abdominal segment slightly sclerotized basally, without distinct hairs near posterior margin on each side. Cercus (Fig. 4J, K) rounded, with 11 or 12 hairs.

Pupa. Body length 2.3-2.5 mm. Head. Integument yellow, moderately covered with small round tubercles (Fig. 5A); antennal sheath without any tubercles; frons with 3 pairs of long trichomes with uncoiled apices (Fig. 5A), and face with pair of simple long trichomes with uncoiled apices (Fig. 5A); 2 of 3 frontal trichomes on each side arising close together, but remaining 1 arising somewhat apart from them, all subequal in length to one another and somewhat longer than facial one. Thorax. Integument yellow, moderately covered with round tubercles, with 3 simple short mediodorsal trichomes arising relatively close together, 2 simple short anterolateral trichomes, 1 simple short posterolateral trichome and 3 simple medium-long ventrolateral trichomes arising relatively close together, on each side (Fig. 5B); 2 simple long trichomes arising very close together below base of gill on each side (Fig. 5B); all with uncoiled apices. Gill (Fig. 5C) composed of 8 slender thread-like filaments, much shorter than pupal body, all individually arising from very short common basal stalk, with swollen transparent organ ventrally (though mostly broken) at base; all filaments light brown, subequal in length $(0.6-0.8 \mathrm{~mm}$ long) and thickness; cuticle of all filaments without marked annular ridges and furrows on outer surface (though basal portion of all filaments with well-marked ridges and furrows on internal surface, Fig. 5D), densely covered with minute tubercles. Abdomen. Dorsally, segment 1 (Fig. 5E) with small tubercles on anterior $1 / 2$ or more, with 1 simple short seta on each side; segment 2 without tubercles, with 1 simple short seta and 5 very short setae submedially (Fig. 5F) on each side; segments 3 and 4 each with 4 hooked spines and 1 very short seta on each side; segment 5 lacking spine- combs; segments 6-9 each with spine-combs in transverse row and comb-like groups of minute spines on each side; segment 9 with pair of distinct conical terminal hooks (Fig. 5G). Ventrally, segment 4 with several simple slender very short setae on each side; segment 5 with pair of bifid hooks submedially and few simple slender very short setae on each side; segments 6 and 7 each with pair of bifid inner and simple outer hooks somewhat spaced from each other and few simple slender very short setae on each side; segments 4-8 with comblike groups of minute spines. Each side of segment 9 with 3 grapnel-shaped hooklets. Cocoon. Wall-pocket shaped, short, covering abdomen and posterior part of thorax of a pupa, moderately and neatly woven, not extending ventrolaterally (Fig. $5 \mathrm{H}$ ) (though somewhat extending ventrolaterally in 1 cocoon, Fig. 5I); anterior margin somewhat thickly woven; floor roughly or moderately woven; individual threads invisible; $1.5-1.8 \mathrm{~mm}$ long by 0.6-1.2 mm wide.

Mature larva. Body length 3.5-4.0 mm. Body somewhat swollen on thoracic segments, narrow on abdominal segments 1-4 (though slightly becoming larger posteriorly), swollen from segment 5 to segment 6 , and narrowed toward posterior end; body yellowish-white except abdominal segments $1-4$ light to dark gray; thoracic segment 1 and abdominal segment 4 each encircled with reddish-brown transverse band, dorsal surface of posterior $1 / 2$ of abdominal segment 5 with reddish-brown transverse band, and dorsal surface of abdominal segments 6-9 reddish-brown entirely or partially. Head capsule whitish-yellow to dark yellow dorsally, laterally and ventrally (Fig. 6 A); all head spots indistinct or faintly positive; eyebrow indistinct. Cervical sclerite composed of 2 small narrow rod-like pieces, not fused to occiput, widely separated medially from each other. Antenna (Fig. 6B) composed of 3 segments and apical sensillum, unpigmented except segment 1 darkened on dorsal surface, longer than stem of labral fan; proportional lengths of 3 segments from base to tip 1.00: $0.79: 0.80$. Labral fan with 40 main rays. Mandible (Fig. 6C) with comb-teeth decreasing in size from 1 st to $3 \mathrm{rd}$; mandibular serrations composed of 2 teeth (1 large, 1 small); large tooth at acute angle to mandible on apical side; supernumerary serrations absent. Hypostoma (Fig. 6D) with 9 apical teeth in row; median 

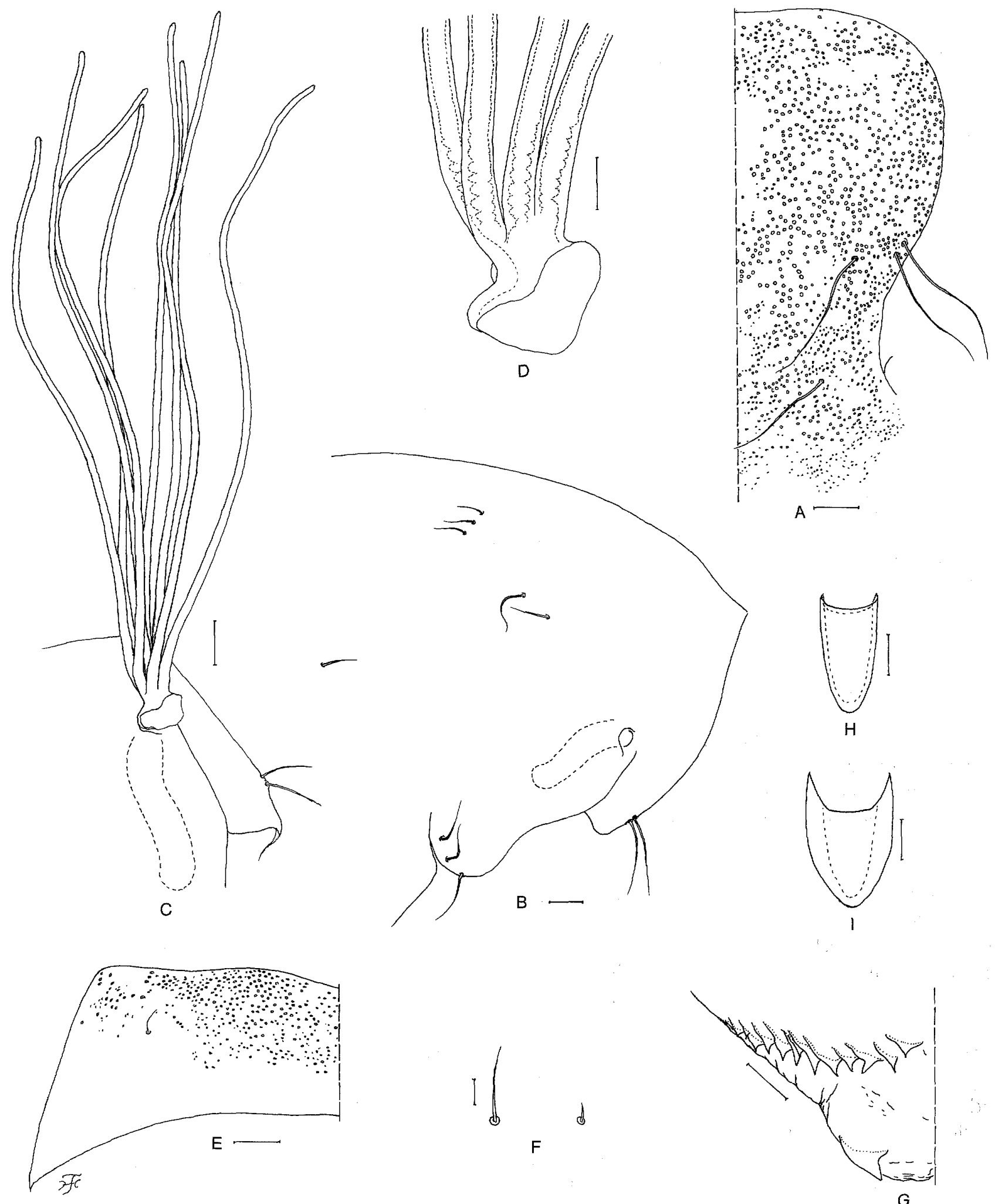

Fig. 5. Pupa of Simulium (Gomphostilbia) fulgidum sp. nov. A, frons and portion of face (left half); B, anterior portion of thorax showing location of trichomes (right side and lateral view); C, gill filaments (right side and lateral view); D, basal portion of outer 4 filaments showing marked annular ridges near base on internal surface (right side and outer view); E, dorsal surface of abdominal segment 1 covered with tubercles (left half and dorsal view); F, short hair-like seta and very short seta on dorsal surface of abdominal segment 2; G, abdominal segment 9 showing terminal hook and spine-combs (left half and dorsal view); $\mathrm{H}$, simple cocoon (dorsal view); I, cocoon with ventrolateral flanks (dorsal view). Scale bars. $0.5 \mathrm{~mm}$ for $\mathrm{H}$ and $\mathrm{I} ; 0.05 \mathrm{~mm}$ for $\mathrm{A}-\mathrm{C}$ and $\mathrm{E} ; 0.02 \mathrm{~mm}$ for $\mathrm{D}$ and $\mathrm{G} ; 0.01 \mathrm{~mm}$ for $\mathrm{F}$. 


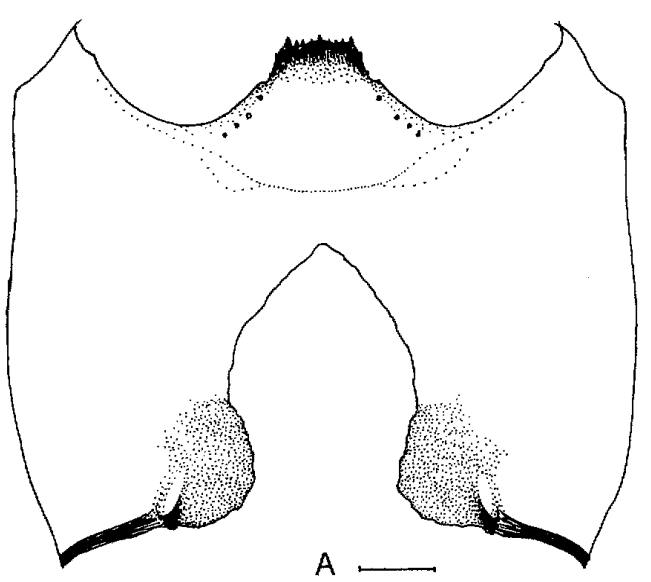

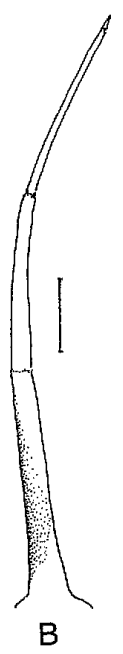

B

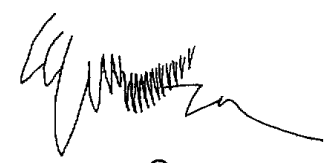

C

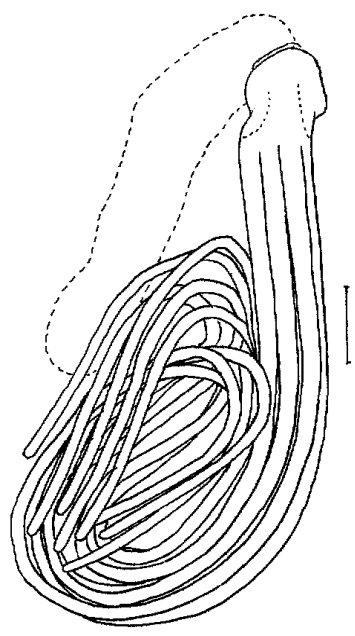

E

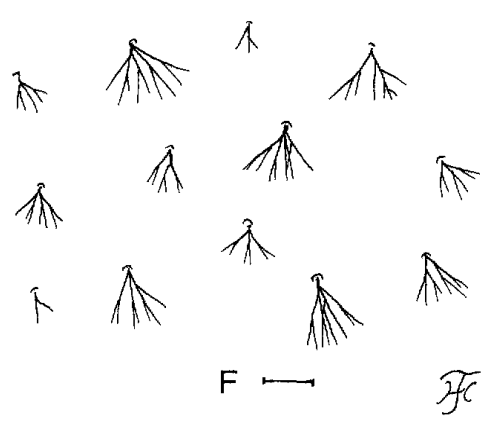

Fig. 6. Mature larva of Simulium (Gomphostilbia) fulgidum sp. nov. A, head capsule showing hypostoma and postgenal cleft (ventral view); B, antenna; C, mandible; D, hypostoma; E, pharate pupal gill (right side and outer view); F, dark branched spinous setae on dorsal surface of abdominal segment 7 . Scales. $0.05 \mathrm{~mm}$ for $\mathrm{A}$ and $\mathrm{B} ; 0.04 \mathrm{~mm}$ for $\mathrm{E} ; 0.02 \mathrm{~mm}$ for $\mathrm{D} ; 0.01 \mathrm{~mm}$ for $\mathrm{C}$ and $\mathrm{F}$.

tooth slightly longer than or as long as each corner tooth; 3 intermediate teeth on each side subequal in length to one another; lateral margin smooth; 4 or 5 hypostomal bristles per side, their sockets aligned nearly parallel to or slightly diverging posteriorly from lateral margin. Postgenal cleft (Fig. 6A) arrow-head shaped, 5.1-6.9 times as long as postgenal bridge. Pharate pupal gill (Fig. 6E) with 8 very slender filaments arising together from base, total width of all these filaments subequal to that of interspiracular trunk. Cuticle of abdominal segments 4-9 moderately or densely covered with dark brown spinous setae split into 2-9 branches (Fig. 6F) dorsally and dorsolaterally, that of abdominal segments $1-3$ and thoracic segments $1-3$ very sparsely covered with similar setae dorsally, and each side of anal sclerite of last segment moderately covered with simple colorless setae (in addition to dark brown branched spinous setae). Rectal scales absent. Rectal organ compound, each of 3 lobes with 5-7 finger-like secondary lobules. Anal sclerite X-shaped, with anterior arms somewhat broadened basally and nearly as long as posterior ones; basal juncture broad, without unsclerotized median incision posteriorly; no sensilla on basal juncture and behind posterior arms; accessory sclerite absent. Ventral papilla well developed. Posterior circlet with $80-83$ rows of up to 13 hooklets per row.

TYPE SPECIMENS. Holotype female with associated pupal exuviae and cocoon (preserved in ethanol), reared from pupa, collected from a stream (width 1-3 m, water temperature $24.0^{\circ} \mathrm{C}$, shaded, altitude $50-60 \mathrm{~m}$ ) moderately flowing in a forest of Mt. Pueh, Pueh, Sematan, Sarawak, Malaysia, 28. VIII. 2008, by H. Takaoka. 
Paratypes: 2 females, 1 male, 3 mature larvae, same data and date as those of the holotype.

ECOLOGICAL NOTES. The pupae and larvae were collected from dead bamboo leaves in the water. Associated species were S. (G.) lehi Takaoka, S. (G.) sarawakense Takaoka, and S. (Simulium) sabahense Smart and Clifford.

ETYMOLOGY. The species name fulgidum refers to the male abdominal segments 2-9 each with a pair of shiny areas. The Latin adjective fulgidus means shining.

REMARKS. This new species is assigned to the batoense species-group by the pleural membrane bare, and the slender male hind basitarsus as well as the usual 11 segments of the adult antennae. The male of $S$. (G.) fulgidum sp. nov. is characterized by the yellow antenna except two apical flagellomeres which are light to medium brown, the yellowish abdominal segments 1 and 2, and the presence of a pair of shiny areas on each of the segments $2-9$. The pupa of this new species is most striking in that it has a short cocoon covering only the pupal abdomen and a posterior part of the thorax (Fig. $5 \mathrm{H}$, I) and eight slender short gill filaments arising from the very short common basal stalk (Fig. 5C). It is noteworthy that a short cocoon coupled with short slender filaments similar to those of $S$. (G.) fulgidum sp. nov. has been reported in $S$. (G.) barioense Takaoka described from Bario, Sarawak (Takaoka, 2008b), and $S$. (G.) montiblense Takaoka described from Palawan, the Philippines (Takaoka, 1983), though these two known species have a different arrangement of the pupal gill filaments.

\section{ACKNOWLEDGEMENTS}

I am grateful to Prof. Peter H. Adler, Clemson University, USA, for reading the manuscript and giving valuable comments. Thanks are due to Dr. Charles Leh, Sarawak Museum, and Prof. Ichiro Miyagi, Ryukyu University, for their support of this study. The field survey was carried out in 2008 under the permission of Sarawak State Department of Forestry. This study was financially supported by a Grant-in-Aid for Oversea Research from the Japan Society for the Promotion of Science (No. 18406011).

\section{REFERENCES}

Delfinado, M. 1971. Some Simuliidae and Curtonotidae from the Philippines and the Bismarck Islands (Insecta, Diptera). Steenstrupia, 1: 131-139.

Edwards, E.W. 1933. Diptera Nematocera from Mount Kinabalu. J. fed. Malay St. Mus., 17: 223296.

Smart, J. and Clifford, E. A. 1969. Simuliidae (Diptera) of Sabah (British North Borneo). Zool. J. Linn. Soc., 48: 9-47.

Takaoka, H. 1983. The Blackflies (Diptera: Simuliidae) of the Philippines. xii +199 pp., Japan Society of the Promotion of Science, Tokyo.

Takaoka, H. 1996. Description of a new species of Simulium (Simulium) from Sabah, Malaysia (Diptera: Simuliidae). Jpn. J. Trop. Med. Hyg., 24: 157161.

Takaoka, H. 2001a. Two new and three newly recorded species of black flies (Diptera: Simuliidae) from Sabah, Malaysia. Jpn. J. Trop. Med. Hyg., 29: 221-230.

Takaoka, H. 2001b. Description of two new species of black flies (Diptera: Simuliidae) from Sarawak, Malaysia. Jpn. J. Trop. Med. Hyg., 29: 243-252.

Takaoka, H. 2003. The Black Flies (Diptera: Simuliidae) of Sulawesi, Maluku and Irian Jaya. xxii +581 pp., Kyushu University Press, Fukuoka.

Takaoka, H. 2007. Two new species of Simulium (Simulium) from Sabah, Malaysia (Diptera: Simuliidae). Med. Entomol. Zool., 58: 291-301.

Takaoka, H. 2008a. Taxonomic revision of tuberosum species-group of Simulium (Simulium) from Sabah and Sarawak, Malaysia (Diptera: Simuliidae). Med. Entomol. Zool., 59: 55-80.

Takaoka, H. 2008b. Four new species of Simulium (Gomphostilbia) (Diptera: Simuliidae) from Sarawak, Malaysia. Med. Entomol. Zool., 59: 181-211. 
Takaoka, H. and Davies, D.M. 1995. The Black Flies (Diptera: Simuliidae) of West Malaysia. viii +175 pp., Kyushu University Press, Fukuoka.

Takaoka, H. and Sigit, H.S. 1992. A new black fly species of Simulium (Gomphostilbia) from Java, Indonesia (Diptera: Simuliidae). Jpn. J. Trop. Med. Hyg., 20: 135-142. 